\title{
Fuga hacia dentro. La novela ecuatoriana en el siglo xx de Alicia Ortega Caicedo
}

\author{
Alexandra Astudillo Figueroa \\ Universidad San Francisco de Quito \\ aastudillo@usfq.edu.ec
}

Recibido: 11 - noviembre - 2018 / Aceptado: 21 - diciembre-2018

\section{Resumen}

En esta obra, Alicia Ortega realiza un cuidadoso análisis para abordar la novela ecuatoriana del siglo XX y la crítica que ha ido surgiendo paralela a dicha producción novelística. Propone una selección de obras y autores que no pretende ser exhaustiva, la que es leída con un cruce analítico interdisciplinario, que le permite dejar atrás posturas dicotómicas, desorganizar el canon y reevaluarlo. Su trabajo es una invitación a repensar los argumentos con los que se ha abortado este corpus, en una tensión creativa continua, que se mueve por el mapa trazado en un viaje abierto y colectivo que explora la localización del contenido social dentro del discurso, el espacio que media entre lenguaje y el referente, y entre sujetos y sus objetos de deseo.

Palabras clave: Ecuador, novela, narrativa, vanguardia, realismo, crítica, siglo $\mathrm{XX}$, canon, historiografía.

\section{Abstract}

In this work, Alicia Ortega makes a careful analysis to address the Ecuadorian novel of the twentieth century and the criticism that has emerged parallel to this novelistic production. It proposes a selection of works and authors that does not pretend to be exhaustive, which is read with an interdisciplinary 
analytical cross, which allows it to leave behind dichotomous positions, disorganize the canon and reevaluate it. His work is an invitation to rethink the arguments with which this corpus has been aborted, in a continuous creative tension, that moves through the map drawn in an open and collective journey that explores the location of the social content within the discourse, the space that mediates between language and the referent, and between subjects and their objects of desire.

Keywords: Ecuador, novel, narrative, avant-garde, realism, criticism, 20th century, canon, historiography. 
E 1 texto de Alicia Ortega Caicedo lleva al lector a un significativo recorrido por la novela ecuatoriana del siglo XX y por la crítica que ha ido surgiendo paralela a la producción novelística. Con una paciente, aguda e incisiva manera de establecer vínculos entre distintas épocas, obras, autores, tendencias, en una suerte de rizoma que va expandiendo las búsquedas de sentido, en distintas direcciones, va poblando las obras que analiza, de una vitalidad que, recupera para el lector, el contrapunto entre la palabra y los sentidos que disemina, entre la creación literaria y la vida que la sustenta, entre la posición crítica y la pregunta por el desde dónde se habla y se escribe.

Este trabajo crítico problematiza la producción novelística ecuatoriana durante el siglo XX, así como la crítica literaria que junto a ella ha ido posicionando a obras y autores dentro de tradiciones y rupturas que han marcado el hacer literario ecuatoriano del siglo pasado. Se lo hace desde una selección que, como toda, es excluyente, pero con un acierto que permite diagramar un mapa que hace posible situar adecuadamente el relieve heterogéneo y los matices que, como tensión permanente, han acompańado tanto a la producción literaria como a la crítica que se ha hecho sobre ella. Un mapa que se presenta desmontable, conquistable, alterable, modificable, con múltiples entradas y salidas.

Esta exploración crítica se aborda a partir de la segmentación del periodo en dos momentos temporales. El primero, conformado por la producción literaria y las obras críticas producidas fundamentalmente en las décadas del treinta y el cuarenta, desde donde se amplía la mirada a los aportes en ambos campos desde inicios del siglo hasta la década de los cincuenta. El segundo, se concentra en las prácticas intelectuales, la producción novelística y el ensayo crítico de finales de los cincuenta hasta el fin de siglo.

La primera parte, a la vez, se abre en tres secciones que, organizadas por la perspectiva temporal, ubican la discusión en la interacción entre la palabra y el contexto en el que emerge y el posicionamiento del escritor.

La primera sección está orientada a leer la resonancia de la revolución liberal en el horizonte cultural de la primera mitad del siglo XX, en esta se profundiza el contrapunto entre la posición del escritor y del crítico, del intelectual orgánico y los obreros y campesinos; se aborda los aportes de escritores y a la vez de críticos sumidos en un rol de "traductores culturales" que analizan la problemática de la literatura y la cultura ecuatorianas desde una posición etnográfica, histórica y sociológica.

Una segunda entrada se centra fundamentalmente en el análisis de varias novelas que se han constituido en hitos para la crítica a la hora de establecer definiciones, señalar trayectorias y tendencias, dentro de una de las discusiones fundamentales del periodo y que ha tenido enorme resonancia posterior. Se trata de las propuestas del realismo y de la vanguardia, respecto de las cuales la autora apuesta por "comprender ambos proyectos como expresiones de un mismo impulso en la compartida tarea 


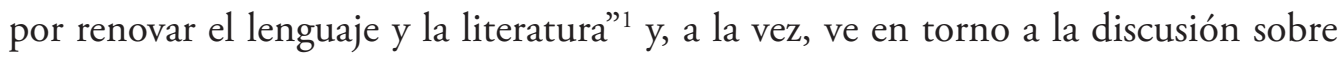
los autores emblemáticos, reeditada muchas veces a lo largo del siglo, un esfuerzo a partir del cual "se legitima la construcción del sujeto intelectual en cada nueva generación”. ${ }^{2}$ La pregunta por lo nacional que atraviesa el sentido de estas propuestas estéticas articula, en la reflexión de Ortega, exploraciones sobre las nociones de raza, clase y género, que instaladas en la geografía nacional son leídas dentro de "un proyecto estético y político de grupo, en tanto referente de una identidad colectiva y múltiple". ${ }^{3}$ La reflexión sobre estas novelas está poblada de preguntas complejas y respuestas que reevalúan lo señalado por la crítica, abren nuevas interrogantes y enriquecen la mirada sobre dichas obras. En cuanto al desarrollo de la crítica literaria en esta segunda línea de análisis, se contrasta una propuesta de matriz eurocéntrica e hispanizante que sustentaron varios intelectuales de la época, con otra en la que las nociones de universalidad, humanismo, americanismo, internacionalismo están atravesadas por los diversos intentos de definir lo nacional, y que encuentran resonancias en otras propuestas latinoamericanas.

Una tercera línea de análisis en esta primera sección es la que abre la discusión sobre el mestizaje y lo que denomina estéticas indigenistas y posindigenistas; se reflexiona sobre el sentido de comunidad, las formas de relacionamiento colectivo, y la presencia de la violencia en diversas instancias de convivencia social. Esta perspectiva permite a la autora convocar dentro de la discusión propuestas estéticas que incorporan sujetos discursivos poco recogidos anteriormente como nińos, migrantes, mujeres que complejizan el abordaje del tema en contextos de neocolonialidad, diferencia y exclusión.

La segunda parte de la obra, como se había señalado, se concentra en la producción literaria y crítica de la segunda mitad del siglo XX, corpus que también es abordado, desde una triple líneas de análisis.

La primera explora la construcción de subjetividades, el horizonte político y las alianzas afectivas que surgen en torno a las representaciones de la figura del intelectual en un corpus de novelas publicadas entre las décadas del 40 y del 60, en las que se trata de comprender cómo se manifiesta el movimiento intelectual de este periodo, "alrededor de qué apuestas, apropiaciones, búsquedas y rupturas". ${ }^{4}$ Una de las preguntas fundamentales que atraviesa este análisis está orientada a la reflexión en torno a la organización del imaginario inmerso en la "consecución de una cultura nacional y de matriz popular"s que tuvo resonancia no solo cultural sino política.

1 Alicia Ortega Caicedo, Fuga hacia dentro. La novela ecuatoriana del siglo XX (Buenos Aires: Corregidor/Universidad Andina Simón Bolívar, Sede Ecuador, 2018), 17.

2 A. Ortega, Fuga hacia dentro, 17.

3 A. Ortega, Fuga hacia dentro, 84.

4 A. Ortega, Fuga hacia dentro, 19.

5 A. Ortega, Fuga hacia dentro, 19. 
En un segundo momento, que aborda la literatura producida en las décadas de los 70 y 80 , sobresalen en su análisis crítico su interés por "los diferentes espacios y trayectorias que consolidaron posibilidades de encuentro y formulación de ideales políticos, así como también la emergencia de nuevas retóricas y proyectos en momentos de desencanto". ${ }^{6}$ Dos preguntas fundamentales orientan las reflexiones sobre este periodo: “¿Cómo lee esta nueva generación a los escritores del treinta, a la vez, desde qué estrategias establecieron su ruptura con respecto a ella? ¿En qué términos elaboró esta generación su crítica a la "ciudad letrada" como instancia oficial de la cultura?". ${ }^{7}$ En este capítulo las reflexiones se orientan a la tarea de pensar la noción de literatura, y de reevaluar categorizaciones y definiciones. Se aborda con agudeza las vinculaciones entre discurso novelístico, crítica literaria y representaciones de la conciencia intelectual, en contextos de militancia política, de exilio, de crisis, de consolidación de políticas neoliberales, no sin dejar de mirar los puntos de contacto con las propuestas político-estéticas de la primera mitad de siglo que reinstalan en el debate la relación entre el intelectual y el pueblo, para evidenciar los complejos cruces entre conciencia política, modernidad, desencanto y escritura literaria. ${ }^{8}$

Una tercera línea, de esta sección, aborda la producción novelística de los 90 . Se evidencia el esfuerzo por leer las propuestas de distintos autores como una reacción frente a la percepción de desencanto manifestada como derrota, redefinición del pasado reciente, nuevas búsquedas, nuevas subjetividades, nuevos abordajes de las nociones de género y raza. En cuanto a la crítica, se analiza propuestas que entrelazan la autonomía estética, la subjetividad del autor, el no lugar del lenguaje y la geografía.

Este trabajo crítico que, si bien está organizado temporalmente, experimenta un desbordamiento de las fronteras temporales a partir del movimiento propuesto en el título: Fuga hacia dentro, que orienta la mirada hacia una exploración interna, recurrente, llena de contrapuntos, que debilita lo temporal. Esta direccionalidad sugerida por el título nos lleva a las siguientes preguntas: ¿de qué se escapa en esta fuga hacia adentro?, ¿qué se deja atrás en esta interiorización crítica? y ¿cuál es el espacio que se puebla?

En esta cuidadosa revisión en la que se convocan múltiples miradas a las que se les descoloca o descentra, se escapa de los lugares comunes, de las preguntas fáciles y de la comodidad de continuar consagrando ciertas posiciones críticas que marcaron la dirección de la mirada, el recorte del corpus, ordenaron las lecturas y orientaron la valoración que consolidó afinidades y rupturas; posiciones que fijaron sentido y direccionalidad a la lectura de la literatura ecuatoriana del siglo XX.

Se trata de una interiorización crítica que deja atrás posturas dicotómicas que han condicionado la mirada sobre la producción literaria del periodo, entre lo

6 A. Ortega, Fuga hacia dentro, 19.

7 A. Ortega, Fuga hacia dentro, 20.

8 A. Ortega, Fuga hacia dentro, 23. 
nacional y lo universal, entre una literatura que hunde sus raíces en la conflictiva realidad nacional y otra que pasa sobre ella, entre la comunidad imaginada y la alegoría nacional, entre la conciencia política, la conciencia ética y la estética, entre la modernidad y el desencanto, entre el conocimiento, la imaginación, la memoria y la fuerza creativa. Desde una selección de obras y autores que no pretende ser exhaustiva se intenta desorganizar el canon, reevaluarlo, proponer otras lecturas que sitúen el sentido en las fisuras de lo dicho, en la tensión vital de los escritores que muchas veces son, a la vez, críticos, historiadores, sociólogos, politólogos. Lo que está en juego, según Ortega "es una forma de comprender la construcción del sujeto en el lenguaje: el sujeto que lo enuncia y el sujeto referido en él. Lo que está en juego es el lugar en el mundo que ese lenguaje construye en el relato, así como el lugar del sujeto en el mundo que hace posible ese lenguaje".?

El espacio que la autora genera y puebla con su propuesta está abierto a un continuo desplazamiento entre la escritura literaria y el momento histórico en el que emerge, no hay jerarquía y la temporalidad como único hilo organizador de su lectura, no le impide regresar sobre obras y propuestas críticas, retomadas en cada época. Establece conexiones con diversas propuestas teóricas para analizar el acto creador, en un viaje abierto con discontinuidades, en las que las entradas interdisciplinarias le permiten potenciar el sentido de lo que se analiza. Hay una búsqueda por explorar las instancias del "entre", relaciones que a manera de rizoma generan conexiones nuevas que permiten evaluar el acto creativo con otras miradas que lo enriquecen.

Otra noción de fuga que resulta útil para recuperar los aportes de Alicia Ortega en este trabajo es la vinculada con la teoría musical.

La fuga, como propuesta de escritura musical que se apoya en el contrapunto, parte de una exposición inicial en la que aparece el tema central en las diversas voces instrumentales, luego, en el desarrollo, se introducen uno o más episodios de gran riqueza moduladora, con variación de tonalidades; una vez realizada esta exposición surge un momento más libre en el que el compositor introduce el tema modificado mediante mecanismos como aumentar o disminuir la duración rítmica, invertir los intervalos que componen el tema o regresar de atrás adelante, fragmentar el material temático, o acompañarlo con recursos contrapuntísticos diversos.

Algo parecido ocurre en el libro, el tema central que se expone a lo largo del recorrido temporal del siglo XX es la novela ecuatoriana desde una particular selección de hitos a partir de los cuales se revisa los espacios que han ido ocupando en la historia de la literatura como de la crítica literaria.

9 A. Ortega, Fuga hacia dentro, 26. 
Las modulaciones que se ofrecen sobre el tema se derivan de la capacidad de propiciar la coincidencia, en un mismo momento crítico creativo, del texto y su autor, la recepción y la crítica, el escenario en que irrumpe y el que evoca, el horizonte político y cultural, "las polémicas que provoca en el circuito de lecturas y apropiaciones" ${ }^{10}$ De esta manera se ofrece, ante los ojos del lector, no solamente la obra en cuestión sino una actualización del debate a través de una cuidadosa reconstrucción de los argumentos fundamentales y el aporte de nuevos elementos críticos con los que se matiza y complementa el conocimiento en torno al tema que se discute. Y de la misma manera como en una orquesta, las distintas propuestas tonales e interpretativas logran el efecto sonoro de conjunto, en el libro, la confluencia en el texto de múltiples entradas argumentativas genera un conocimiento producto de una elaboración crítica que "lleva la marca de una autoría colectiva". ${ }^{11}$

La sección más libre de la composición musical corresponde en el libro al contrapunto generado por la continua pregunta por el lugar de enunciación de la obra literaria y por el lugar desde donde se lee, por el lugar de la interpretación. Este contrapunto argumenta con fuerza que toda posición enunciativa está contaminada por el lugar de enunciación de su autor, ${ }^{12}$ locación que no puede prescindir de las implicaciones geopolíticas y socioculturales. Hay una honesta búsqueda de autenticidad que, para Ortega en contextos poscoloniales pasa necesariamente por gestos de recuperación simbólica y reinvención del sentido de pertenencia. ${ }^{13}$ El retorno a la inversa del contrapunto musical se visualiza en el libro a través de una lectura en reversa o de una lectura en contra que genera espacios de disputa y de polémica.

A diferencia de la fuga musical que tiene un final, la obra propone un cierre, pero no un final, las preguntas que formula en los distintos acápites siguen interpelando al lector, animando a continuar el debate, a repensar los argumentos en una tensión creativa continua, que se mueve por el mapa trazado en un viaje abierto y colectivo que explora la localización del contenido social dentro del discurso, el espacio que media entre lenguaje y el referente, y entre sujetos y sus objetos de deseo.

Finalmente, podría decir, que se trata de un libro levantado con paciencia de orfebre, enormemente sentido, con una afectividad tanto por el trabajo crítico como por el objeto de la investigación, con una clara posición ética que explora con honestidad los efectos del lenguaje en la formación de una visión crítica que también es política.

\footnotetext{
10 A. Ortega, Fuga hacia dentro, 434.

11 A. Ortega, Fuga hacia dentro, 434.

12 A. Ortega, Fuga hacia dentro, 444.

13 Said en Ortega, 448.
} 